\title{
MORFOLOGIA COMPARATIVA DO TUBO DIGESTÓRIO DE CICHLASOMA SP. E GEOPHAGUS SP. (CICHLIFORMES, CICHLIDAE)
}

Leonilde Xavier Costa ${ }^{1}$, Alaor Maciel Júnior², Cláudia Maria Reis Raposo Maciel², Jeane Campos Silva ${ }^{3}$, Rafaela Porto Silva ${ }^{1}$

1 Discente do curso de Zootecnia e Bolsista do PIBIC da Universidade Estadual do Sudoeste da Bahia / UESB, Itapetinga, BA. Email: leozinhaxavier_@hotmail.com 2 Docente da Universidade Estadual do Sudoeste da Bahia / UESB, Laboratório de Biologia, Itapetinga, BA.

3 Discente do curso de Ciências Biológicas da UESB, Itapetinga, BA.

Recebido em: 03/10/2016 - Aprovado em: 21/11/2016 - Publicado em: 05/12/2016 DOI: 10.18677/EnciBio 2016B 115

\section{RESUMO}

Objetivou-se estudar comparativamente a morfologia do aparelho digestório de duas espécies de ciclídeos presentes no rio Catolé Grande, em Itapetinga, BA, utilizou-se 20 exemplares de peixes pertencentes à família Cichilidae, ordem Cichliformes, espécies Cichlasoma sp. e Geophagus sp., coletados no trecho urbano do rio. Em ambas as espécies o esôfago apresentou-se como um tubo cilíndrico, curto, limitado anteriormente pelos arcos branquiais e posteriormente pelo estômago, localizandose na porção posterior ao septo transverso. As espécies apresentaram estômagos do tipo cecal, sendo que Geophagus sp. apresentou estômago cecal em " $Y$ ", e a espécie Cichlasoma sp., estômago cecal em "J". O estômago das espécies era um órgão definido, sendo possível identificar três regiões distintas: a região cárdica, região cecal e a região pilórica. O intestino médio era disposto em forma de espiral, enovelado e suas alças ligadas por tecido conjuntivo, em ambas espécies analisadas. Quando se observou a porção anterior da mucosa intestinal, verificou-se a presença de pregas longitudinais nas espécies estudadas, que provavelmente atuam no direcionamento do alimento e, além disso, ampliam a superfície de contato favorecendo a absorção de nutrientes. Observaram-se diferenças na disposição e tamanho das pregas, Cichlasoma sp. apresentou três pregas primárias e sulcos bem evidentes, sendo elas mais espessas e largas em comparação a Geophagus sp., em que as pregas se apresentaram mais delgadas e estreitas. As adaptações tróficas verificadas nas espécies avaliadas retrataram os hábitos alimentares distintos, preferencialmente invertívoro, em Geophagus sp., e onívoro, com tendência a invertivoria, em Cichlasoma sp.

PALAVRAS-CHAVE: Anatomia, Cichlidae, Esôfago, Estômago, Intestino

\section{COMPARATIVE MORPHOLOGY OF DIGESTIVE TUBE OF CICHLASOMA SP. AND GEOPHAGUS SP. (PERCIFORMES, CICHLIDAE)}

\begin{abstract}
In order to study comparatively the morphology of the digestive system in two cichlid species present in the Catolé Grande river, in Itapetinga, BA, were used 20 specimens of fish belonging to the order Cichliformes and Cichilidae family,
\end{abstract}


Cichlasoma sp. and Geophagus sp. collected in the urban section of the river. In both species the esophagus appeared as a cylindrical tube, short, limited anteriorly by the gill arches and, posteriorly, by the stomach, located in the posterior portion of the transverse septum. The species presented stomachs of cecal kind, Geophagus sp. presented cecal "Y" and Cichlasoma sp., cecal "J". The stomach of the species was a specific organ, and it was possible to identify three distinct regions: the cardia, the cecal and the pyloric. The midgut of both species was arranged in a spiral shape, and its loops linked by connective tissue. When observed the anterior portion of the intestinal mucosa, it was verified the presence of longitudinal folds the species studied, which probably act in the food direction and, in addition, increase the contact surface and, consequently, promote the absorption of nutrients. Differences in the layout and size of folds were observed. Cichlasoma sp. presented three primary folds and grooves very evident, being thicker and wider in comparison to Geophagus sp., wherein the folds were thinner and narrower. The trophic adaptations observed in both species reflected their distinct feeding habits, preferentially invertivorous in Geophagus sp., and omnivorous, with tendency to invertivory in Cichlasoma sp.

KEYWORDS: Anatomy, Cichlidae, Esophagus, Intestine, Stomach

\section{INTRODUÇÃO}

O rio Catolé Grande é um importante afluente do rio Pardo, cuja sub-bacia abrange uma área de cerca de $3.100 \mathrm{Km}^{2}$. Esta é circundada por um conjunto de serras e uma área deprimida e plana, que facilita o escoamento do rio (LIMA \& PINTO, 2011). A cidade de Itapetinga (BA) é banhada por este rio, sendo importante fonte de renda para ribeirinhos, para o abastecimento humano, como fonte de irrigação e, ainda, é de grande relevância para a pecuária, principal atividade da região.

Diante da diversidade de espécies de peixes descritas no rio Catolé Grande, destacam-se as da família Cichlidae. Das características marcantes do grupo, verifica-se prontamente a presença dos raios anteriores das nadadeiras dorsal e anal, e o primeiro raio da ventral, transformados em espinhos e a linha lateral interrompida, dividida em dois ramos: superior e inferior (MENEZES et al., 2007). Os ciclídeos possuem hábitos diurnos e preferência por ambientes lênticos. Apresentam cuidado parental, protegendo ovos e jovens, e fazem ninhos (BRITSKI et al., 2007). Em recente abordagem filogenética, essa família foi revisada por BETANCUR-R. et al. (2013) sendo que, atualmente, pertence à Ordem Cichliformes.

Cichlasoma sp. é um ciclídeo de pequeno porte, com hábitos territorialistas, utilizado com peixe ornamental (VAZ et al., 2000), sendo espécie onívora, com tendência a invertivoria. Geophagus sp., por sua vez, é uma espécie encontrada em quase todos os tipos de ambientes e alimenta-se preferencialmente de invertebrados que revolvem o substrato e de detritos (OYAKAWA et al., 2006).

As variações na estrutura do aparelho digestório dos peixes têm estreita relação com o tipo de alimento ingerido e ambiente. De acordo com GONÇALVES et al. (2013), muitos autores ressaltaram a importância do conhecimento da anatomia deste aparelho nos peixes, por apresentar variações e indicar a diversidade das dietas, bem como os modos de vida.

MACIEL et al. (2009) salientaram que as primeiras etapas a serem consideradas nos estudos relacionados à alimentação e nutrição de uma espécie de peixe são a morfologia e fisiologia do aparelho digestório, assim como os hábitos e comportamentos alimentares na natureza. Para COSTA et al. (2015), o conhecimento da anatomia do sistema digestório dos peixes fornece subsídios para 
diversas áreas de pesquisa e desenvolvimento para a manutenção e conservação dos estoques pesqueiros.

Desse modo, objetivou-se descrever e comparar a anatomia do tubo digestório dos ciclídeos, Cichlasoma sp. e Geophagus sp., coletados no rio Catolé Grande, no município de Itapetinga, Bahia, relacionando-a aos hábitos alimentares dessas espécies.

\section{MATERIAL E MÉTODOS}

Foram utilizados 20 exemplares adultos de peixes pertencentes à ordem Cichliformes, família Cichlidae, sendo 10 de cada espécie, Cichlasoma sp. e Geophagus sp., que foram coletados no rio Catolé Grande, no município de Itapetinga, BA, em 2012 e 2016. Os exemplares foram fixados em solução aquosa de formol a 10\%, armazenados em álcool etílico a 70\%, e constavam da coleção ictiológica do Laboratório de Biologia da Universidade Estadual do Sudoeste da Bahia - UESB, Campus Juvino Oliveira, em Itapetinga, Bahia.

A biometria dos exemplares foi realizada com auxílio de paquímetro digital, com precisão de $0,01 \mathrm{~mm}$, e as fotografias foram obtidas com câmara fotográfica digital. Para o estudo morfológico, dois exemplares de cada espécie foram dissecados de acordo com AMLACHER (1964) e quatro foram seccionados em planos sagital mediano, frontal e transversal, conforme descrito por MENIN \& MIMURA (1993). Para descrição do padrão da mucosa dos órgãos do tubo digestório, fez-se a incisão e as paredes rebatidas e fixadas, com auxílio de alfinetes, em placa de petri preenchida com parafina. Utilizou-se microscópio estereoscópico com aumento máximo de 40x para auxiliar a descrição.Considerouse a divisão do tubo digestório em: intestino anterior (esôfago e estômago), intestino médio (intestino propriamente dito) e intestino posterior (reto e ânus), conforme MENIN \& MIMURA (1993) e BARCELLOS et al. (2014).

Todo o trabalho foi conduzido seguindo os Princípios Éticos para o Uso de Animais de Laboratório, publicado pelo Colégio Brasileiro de Experimentação Animal - COBEA, e os exemplares foram coletados com autorização do Instituto Brasileiro do Meio Ambiente e dos Recursos Naturais Renováveis - IBAMA e Instituto Chico Mendes de Conservação da Biodiversidade (ICMBio) para atividade com finalidade científica, nำ 30820-1, emitida pelo SISBIO - Sistema de Autorização e Informação de Biodiversidade.

\section{RESULTADOS E DISCUSSÃO}

Os dados morfométricos dos exemplares e do tubo digestório estão expressos nas Tabelas 1 e 2 respectivamente.

TABELA 1. Valores médios do comprimento-padrão (CP) e comprimento-total (CT), em milímetros (mm), dos ciclídeos Cichlasoma sp. e Geophagus sp. do rio Catolé Grande, Itapetinga, BA.

\begin{tabular}{cccccc}
\hline Espécie & $\mathbf{n}$ & $\mathbf{C P}(\mathbf{m m})$ & $\mathbf{C P}$ amplitude & $\mathbf{C T}(\mathbf{m m})$ & CT amplitude \\
\hline Cichlasoma sp. & 10 & 48,87 & $41,82-62,37$ & 63,03 & $51,98-78,25$ \\
Geophagus sp. & 10 & 50,33 & $45,00-58,09$ & 61,81 & $49,50-74,15$
\end{tabular}

$\mathrm{n}=$ número de exemplares de cada espécie. 
TABELA 2. Dados morfométricos em milímetros $(\mathrm{mm})$ do tubo digestório de Cichlasoma sp. e Geophagus sp. do rio Catolé Grande, Itapetinga, BA.

\begin{tabular}{cccccc}
\hline Espécie & $\mathbf{n}$ & Esôfago & Estômago & Intestino & $\begin{array}{c}\text { Tubo } \\
\text { digestório }\end{array}$ \\
\hline Cichlasoma sp. & 10 & 0,2 & 4,84 & 134,83 & 143,44 \\
Geophagus sp. & 10 & 0,2 & 2,53 & 55,54 & 60,36 \\
\hline
\end{tabular}

n = número de exemplares de cada espécie.

$\mathrm{Na}$ cavidade peritoneal, o tubo digestório das espécies no que diz respeito à sua disposição, ocorreu de modo semelhante a outras espécies descritas na literatura (SEIXAS FILHO et al., 2003; BARCELLOS et al., 2014; MORAIS et al., 2014; COSTA et al., 2015), e ocupava, pelo menos, os dois terços anteriores da cavidade. A forma da cavidade peritoneal acompanhou o padrão corporal das espécies, que é comprimido e os órgãos do tubo digestório não a preenchem totalmente, sendo mais volumosos em Cichlasoma sp. (Figura 1).
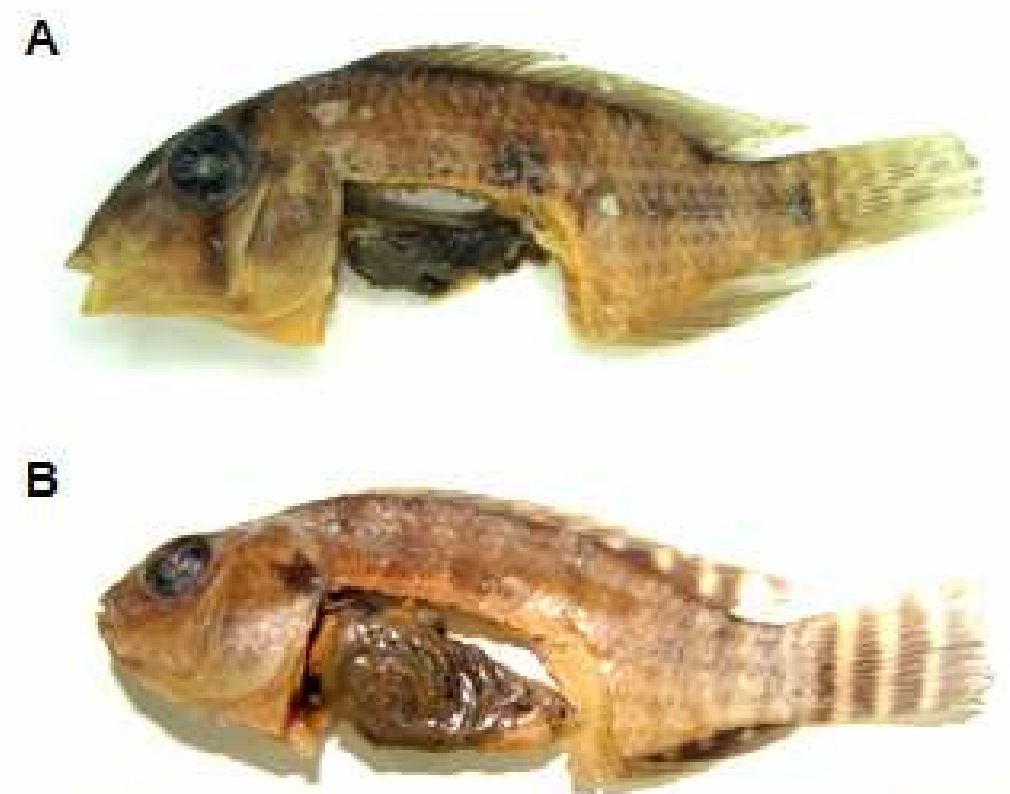

FIGURA 1. Cavidade peritoneal de Geophagus sp. (A) e Cichlasoma sp. (B), coletados no rio Catolé Grande, Itapetinga, BA, evidenciando os tubos digestórios. (Fonte: Autores.)

Em corte sagital mediano de Cichlasoma sp. e Geophagus sp. foi visualizada a disposição dos aparelhos digestórios, bem como outros órgãos, como encéfalo e bexiga natatória (Figuras 2 e 3 ). 


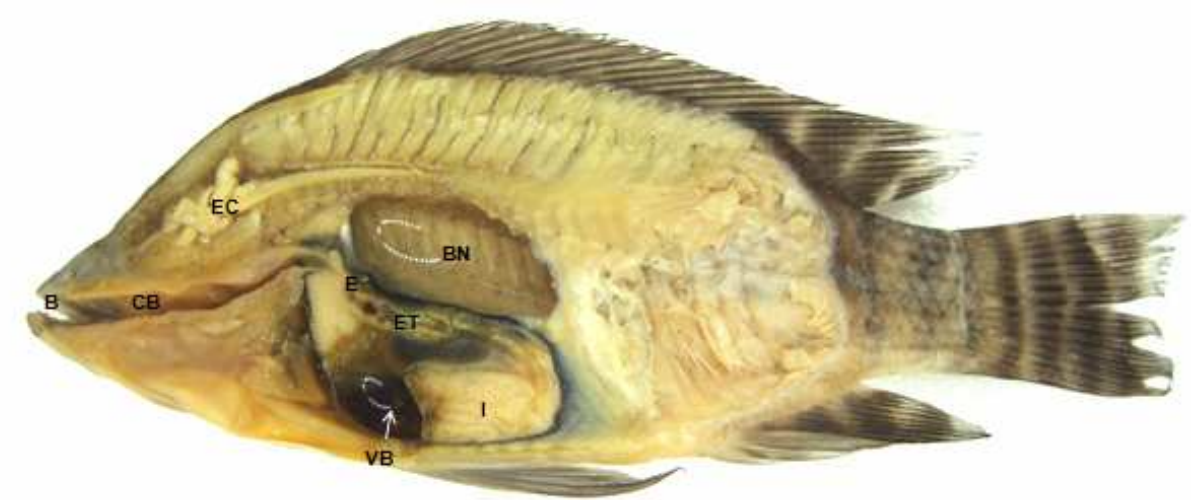

FIGURA 2. Corte sagital mediano, antímero direito, de Cichlasoma sp. do rio Catolé Grande, Itapetinga, BA, evidenciando o aparelho digestório, encéfalo e a bexiga natatória. B) Boca; BN) Bexiga natatória; CB) Cavidade bucal; E) Esôfago; EC) Encéfalo; ET) Estômago; I) Intestino VB) Vesícula biliar. (Fonte: Autores.)

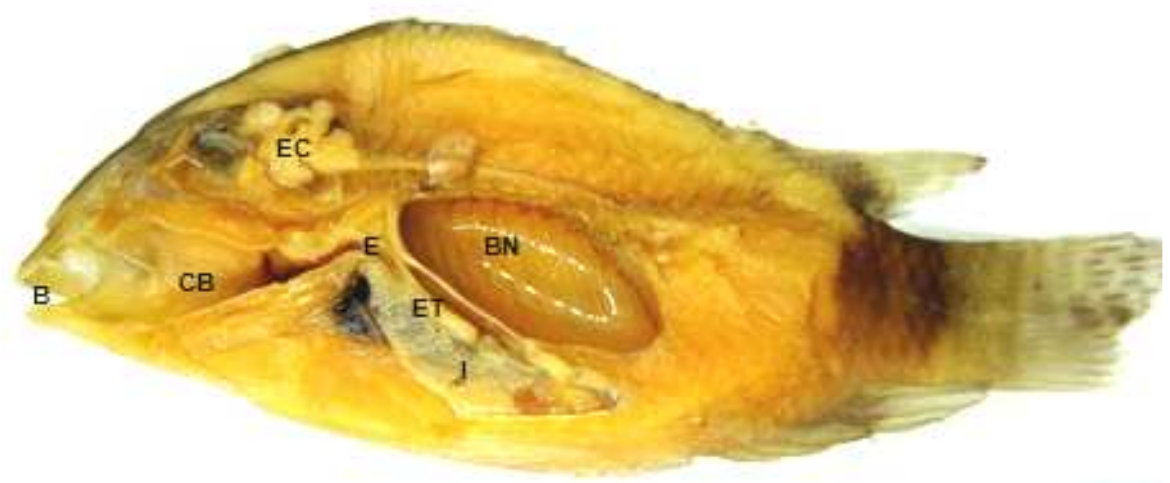

FIGURA 3. Corte sagital mediano, antímero direito, de Geophagus sp. do rio Catolé Grande, Itapetinga, BA, evidenciando o aparelho digestório, encéfalo e bexiga natatória. B) Boca; BN) Bexiga natatória; CB) Cavidade bucal; E) Esôfago; EC) Encéfalo; ET) Estômago; I) Intestino. (Fonte: Autores)

O esôfago das espécies se apresentou como um tubo cilíndrico, curto, limitado anteriormente pelos arcos branquiais e, posteriormente, pelo estômago, sendo de difícil identificação, como descrito por MENIN \& MIMURA (1993), BARCELLOS et al. (2014) e COSTA et al. (2015). A parede esofágica era espessa, mantendo-se constante ao longo do órgão, e distensível, não oferecendo obstáculos à passagem do alimento.

ROTTA (2003) descreveu o esôfago de peixes como um tubo quase sempre curto, largo, retilíneo e musculoso, cuja função é degustar o alimento (possui corpúsculos gustativos) e direcioná-lo até o estômago por meio das ondas peristálticas, que são contrações musculares cuja função é transportar os alimentos pelo trato gastrointestinal, misturá-los com os sucos digestivos e permitir o contato dos nutrientes digeridos com a mucosa, para sua subsequente absorção.

Além de conduzir os alimentos da boca para o estômago ou intestino, 0 esôfago pode comunicar-se com a bexiga gasosa, por meio do ducto pneumático, e 
desempenhar diferentes funções, como a osmorregulação em peixes eurialinos ou, ainda, auxiliar na respiração (MENIN \& MIMURA, 1993). As espécies estudadas apresentaram estômagos do tipo cecal, sendo que Geophagus sp. apresentou estômago cecal em "Y", e Cichlasoma sp., cecal em "J" (Figura 4).

Conforme OLSSON (2011), a depender da forma, o estômago pode ser classificado em três tipos: retilíneo (sacular, com lúmen grande), sifoide (semelhante a um sifão, em forma de "U" ou "J", com lúmen amplo) e cecal (em forma de "Y" e característico de espécies que ingerem grandes itens alimentares de uma só vez). Em adição, ROTTA (2003) dividiu o estômago em três regiões: cárdica (anterior), cecal ou fúndica (intermediária, sacular) e pilórica (posterior). O mesmo autor salientou que as regiões cárdica e pilórica possuem esfíncteres que controlam a passagem dos alimentos pelo estômago. Os estômagos das espécies estudadas apresentaram-se como órgãos bem definidos, sendo possível identificar as três regiões distintas (Figura 4).

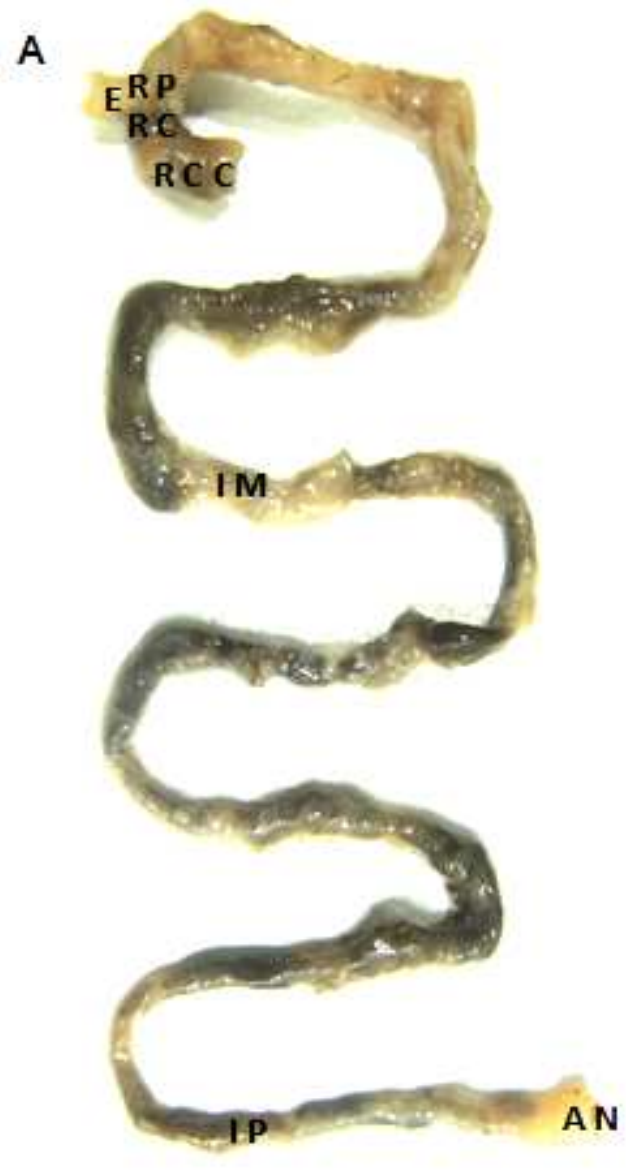

B

FIGURA 4. Estrutura dos tubos digestórios de Cichlasoma sp. (A) e Geophagus sp. (B) do rio Catolé Grande, Itapetinga, BA. E) Esôfago; Estômago: RC) região cárdica, $\mathrm{RCC}$ ) região cecal e $\mathrm{RP}$ ) região pilórica; IM) Intestino médio; IP) Intestino posterior e AN) Ânus. (Fonte: Autores.)

De acordo com MORAIS et al. (2014), o estômago do tipo sacular ou em "Y" permite a ingestão de presas inteiras, ocorrendo a distensão das paredes estomacais, em especial nas regiões cárdica e fúndica. Em ambas as espécies 
verificou-se a presença de esfíncter cárdico na porção anterior do estômago e esfíncter pilórico na porção posterior do mesmo. A função dos esfíncteres é controlar a taxa de fluxo do alimento, evitando o refluxo para o esôfago e estômago (OLSSON, 2011), respectivamente, permitindo maior tempo de exposição do alimento ao suco gástrico e controlando a sua passagem para o intestino (RUST, 2002). Também foram verificadas pregas mais espessas no estômago de Geophagus sp., que contribuem para a distensibilidade do órgão.

O intestino propriamente dito estava disposto em forma de espiral, enovelado e ligado por tecido conjuntivo. Em Geophagus sp., este foi subdividido em três alças intestinais e em Cichlasoma sp., em seis alças, que se encontravam interligadas pelo mesentério de tecido conjuntivo. ANGELESCU \& GNERI (1949) mencionaram que o grande número de circunvoluções intestinais possibilita maior absorção de nutrientes, devido ao lento trânsito do bolo alimentar.

Segundo GONÇALVES et al. (2013), o intestino geralmente é tubular e com essa forma, o aumento ou diminuição da superfície de absorção será estabelecido pelo comprimento do mesmo, e a função primária é completar a digestão iniciada no estômago e absorver nutrientes, água e íons. PESSOA et al. (2013) relataram que, dentre as variações verificadas no intestino de peixes, as relacionadas à anatomia e ao comprimento são as mais específicas.

KAPOOR et al. (1975) relacionaram o tamanho do intestino com o tipo de alimento ingerido. Segundo estes autores, em geral, intestinos mais longos ocorrem em espécies que se alimentam de itens pouco digestíveis, como as herbívoras e detritívoras, ao passo que intestinos mais curtos são encontrados em espécies carnívoras. Peixes onívoros, de modo geral, apresentam comprimento intestinal intermediário variando conforme a proporção dos diferentes tipos de alimentos consumidos. GONÇALVES et al. (2013) também relacionaram o tamanho do intestino com o tipo de alimento e a facilidade de digestão do mesmo, havendo uma relação positiva quanto ao aumento do coeficiente intestinal e a dificuldade de digestão da presa.

O intestino mais longo verificado em Cichlasoma sp. é função direta da sua dieta e do seu valor nutricional, já que a porção utilizável da massa lodosa é reduzida em relação ao total ingerido. Assim, os peixes devem ingerir grandes quantidades de alimento, que repercute no aumento do volume da cavidade geral do corpo para alojar o conduto intestinal. O número de voltas intestinais garante um trânsito lento do alimento, permitindo uma absorção mais efetiva dos nutrientes (MORAES et al., 1997).

Quando se observou a porção anterior do intestino médio, verificou-se pregas longitudinais que atuariam no direcionamento do alimento, aumentando a superfície de contato e, consequentemente, a absorção de nutrientes. Ambas as espécies apresentaram tais pregas, entretanto, observaram-se diferenças na sua disposição. Em Cichlasoma sp. verificou-se três pregas primárias e sulcos evidentes, sendo elas mais espessas e largas, já em Geophagus sp., elas estavam dispostas de forma mais delgadas e estreitas (Figura 5). 


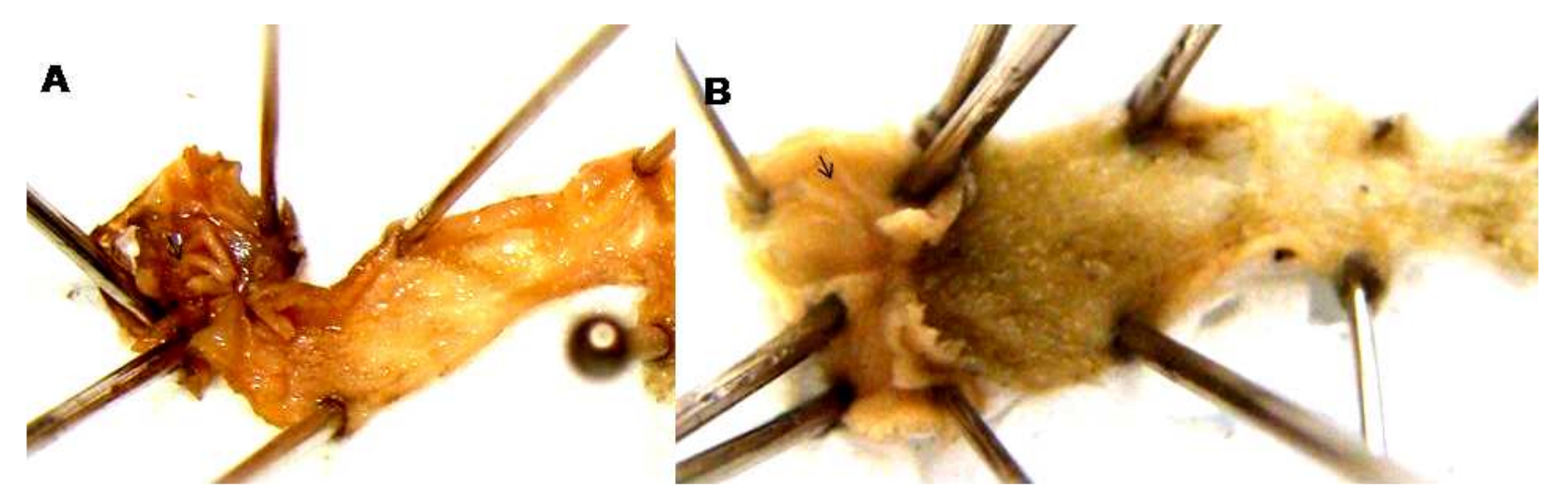

FIGURA 5. Porção anterior do intestino médio de Cichlasoma sp. (A) e Geophagus sp. (B) do rio Catolé Grande, Itapetinga, BA, evidenciando as pregas da mucosa. (Fonte: Autores).

Segundo ROTTA (2003), as pregas da mucosa intestinal também estão relacionadas com 0 transporte do material em processamento: pregas longitudinais auxiliam o trânsito desse material, acelerando-o, ao passo que, pregas transversais retardam o mesmo, atuando como obstáculos à sua passagem.

BARCELLOS et al. (2014) ressaltaram que a mucosa intestinal pregueada, que varia em complexidade dentre as espécies, implica na retenção do alimento por maior tempo e ampliação da sua área de absorção. No intestino posterior dos ciclídeos estudados foi identificado o reto, com parede muscular mais espessa que a do intestino e o padrão longitudinal das pregas verificado pode ser a estrutura facilitadora para a passagem do alimento digerido e expulsão do bolo fecal para o exterior (MENIN \& MIMURA, 1993).

\section{CONCLUSÕES}

As espécies possuem um tubo digestório completo e as adaptações tróficas verificadas em Geophagus sp. e Cichlasoma sp. retrataram hábitos alimentares distintos, preferencialmente invertívora, e onívora, com tendência a invertivoria, respectivamente.

\section{REFERÊNCIAS}

AMLACHER, E. Manual de enfermidades de los peces. Zaragoza: Editorial Acribia, 1964. 319p.

ANGELESCU, V.; GNERI, F. S. Adaptaciones del aparato digestive al regimen alimentício en algunos peces del Rio Uruguay y del Rio de La Plata. Revista del Instituto Nacional de Investigación de las Ciências naturales, v. 1, p. 161-275. 1949.

Disponível em:

http://www.efn.unc.edu.ar/otros/bibliocentro/index_archivos/doc74.PDF>.

BARCELLOS, J. F. M.; BRANCO, E.; PONTES, D. Aspectos morfométricos do tubo digestório de Roeboides xenodon e Orthospinus franciscencis. Revista Biotemas, v. 27, n. $3, \quad$ p. 139-147, 2014. Disponível em: $<$ https://periodicos.ufsc.br/index.php/biotemas/article/viewFile/21757925.2014v27n3p139/27669>. DOI: $\quad$ http://dx.doi.org/10.5007/21757925.2014v27n3p139 
BETANCUR-R., R., R. E.; BROUGHTON, E. O.; WILEY, K.; CARPENTER, J. A.; LOPEZ, C.; LI, N. I.; HOLCROFT, D.; ARCILA, M.; SANCIANGCO, J.; CURETON, F.; ZHANG, T.; BUSER, M.; CAMPBELL, T.; ROWLEY, J. A.; BALLESTEROS, G.; LU, T.; GRANDE, G.; ARRATIA. G.; ORTÍ. The tree of life and a new classification of bony fishes. PLoS Currents Tree of Life. p. 1-28, 2013. Apr 18. Disponível em: https://www.ncbi.nlm.nih.gov/pubmed/23653398

DOI:

10.1371/currents.tol.53ba26640df0ccaee75bb165c8c26288.

BRITSKI, H. A; SILIMON, K. Z. S; LOPES, B. S. Peixes do Pantanal. Manual de Identificação. Brasília: Embrapa-SPI; Corumbá: Embrapa Informação Tecnológica, 2007, 227p.

COSTA, G. M.; VIEIRA, B. S.; LIMA, M.; SCHUINGUES, C. O.; OLIVEIRA, L. C. Anatomia do tubo digestório de Leporinus fasciatus (BLOCK, 1794) (Teleostei, Anastomidae). Enciclopédia Biosfera, v. 11, n. 22, p. 2820-2851, 2015. Disponível em:<https://www.researchgate.net/publication/285547997_ANATOMIA_DO_TUBO_ DIGESTORIO_DE_Leporinus_fasciatus_BLOCK_1794_TELEOSTEO_ANOSTOMID

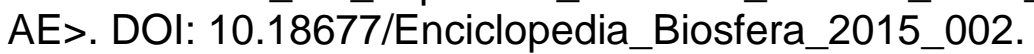

GONÇALVES, L. U.; RODRIGUES, A. P. O.; MORO, G. V.; CARGNIN-FERREIRA, E.; CYRINO, J. E. P. Morfologia e Fisiologia do Sistema Digestório de Peixes. p.936. In: FRACALOSSI, D. M.; CYRINO, J. E. P. (eds.) Nutriaqua: nutrição e alimentação de espécies para a aquicultura brasileira, Florianópolis: Sociedade Brasileira de Aquicultura e Biologia Aquática, 2013, xxiii, 375p.

KAPOOR, B. G.; SMIT, H.; VERIGHINA, I.A. The alimentary canal and digestion in teleosts. Advances in Marine Biology, v. 13, p. 109-239, 1975.

LIMA, E. M.; PINTO, J. E. S. S. P. Bacia do rio Catolé, Bahia - Brasil: Bases geoambientais e socioeconômicas para a gestão da água e do solo. Revista Geográfica de América Central, v. 2, n. 47E, 2011. Disponível em: <http://www.revistas.una.ac.cr/index.php/geografica/article/view/2691>.

MACIEL, C. M. R. R.; MACIEL-JÚNIOR, A.; LANNA, E. A. T.; MENIN, E. Anatomia funcional da cavidade bucofaringiana de trairão Hoplias lacerdae Miranda Ribeiro, 1908 (Characiformes, Erytrinidae). Biotemas, v. 22, p. 95-102, 2009. Disponível em: <file:///C:/Users/User/Downloads/19531-61804-1-PB\%20(1).pdf>.

MENEZES, N. A.; WEITZMAN, S. H.; OYAKAWA, O. T.; LIMA, F. C. T.; CASTRO, R. M. C.; WEITZMAN, M. J. Peixes de água doce da Mata Atlântica. Lista preliminar das espécies e comentários sobre a conservação de peixes de água doce Neotropicais. São Paulo: Museu de Zoologia, Universidade de São Paulo, 2007. $408 p$.

MENIN, E.; MIMURA, O. M. Anatomia comparativa do esôfago de seis peixes Teleostei de água doce de distintos hábitos alimentares. Revista Ceres, v. 40, n. 230, $\quad$ p. 334-369, $1993 . \quad$ Disponível em: <http://www.ceres.ufv.br/ojs/index.php/ceres/article/view/2207/245>. 
MORAES, M. F. P. G.; BARBOLA, I. F.; GUEDES, E. A. Alimentação e relações morfológicas com 0 aparelho digestivo de "curimbatá", Prochilodus lineatus (Valenciennes) (Osteichthyes, Prochilondontidae) de uma lagoa do sul do Brasil. Revista Brasileira de Zoologia, v. 14, n. 1, p. 169-180, 1997.

MORAIS, A. L. S.; CARVALHO, M. M.; CAVALCANTE, L. F. M.; OLIVEIRA, M. R.; CHELLAPPA, S. Características morfológicas do trato digestório de três espécies de peixes (Osteichthyes: Lutjanidae) das águas costeiras do Rio Grande do Norte, Brasil. Biota Amazônia, v. 4, n. 2, p. 51-54, 2014. Disponível em: < https://periodicos.unifap.br/index.php/biota/article/view/824>.

DOI: http://dx.doi.org/10.18561/2179-5746/biotaamazonia.v4n2p51-54.

OLSSON, C. The gut. Gut anatomy and morphology: Gut anatomy. P. 1268-1275. In: FARRELL, A. P. (ed.) Gas Exchange, Internal Homeostatis, and Food Uptake. Encyclopedia of Fish Physiology: From Genome to Environment. Academic Press: San Diego, CA, USA. 2011.

OYAKAWA, O. T.; AKAMA, A.; MAUTARI, K. C.; NOLASCO, J. C. Peixes de Riachos de Mata Atlântica. São Paulo: Editora Neotropica, 2006. 203p.

PESSOA, E. K. R.; SILVA, N. B.; CHELLAPPA, N. T.; SOUZA, A. A.; CHELLAPPA, S. Morfologia comparativa do trato digestório dos peixes Hoplias malabaricus e Hypostomus pusarum do açude Marechal Dutra, Rio Grande do Norte, Brasil. Biota Amazônia, v. 3, n. 1, p. 48-57, 2013. Disponível em:< https://www.researchgate.net/publication/254559145_Morfologia_Comparativa_do_T rato_Digestorio_dos_Peixes_Hoplias_malabaricus_e_Hypostomus_pusarum_do_Ac ude_Marechal_Dutra_Rio_Grande_do_Norte_Brasil>.

DOI: http://dx.doi.org/10.18561/2179-5746/biotaamazonia.v3n1p48-57.

ROTTA, M. A. Aspectos Gerais da Fisiologia e Estrutura do Sistema Digestivo dos Peixes Relacionados à Piscicultura. EMBRAPA, 2003,49p. Disponível em:< http://www.cpap.embrapa.br/publicacoes/online/DOC53.pdf>.

RUST, M. B. Nutritional Physiology. p. 367-505. In: HALVER, J. E.; HARDY, R. W. (ed.) Fish Nutrition. Academic Press: San Diego, Ca. USA, 2002.

SEIXAS-FILHO, J. T., BRÁS, J. M., GOMIDE, A. T. M., OLIVEIRA, M. G. A., DONZELE, J. L.; MENIN, E. Anatomia funcional e morfometria do intestino do Teleostei (Pisces) de água doce surubim (Pseudoplatystoma coruscans Agassiz, 1829). Revista Brasileira Zootecnia, v. 30, n. 6, p. 01-13, 2003. Disponível em:< http://www.scielo.br/scielo.php?script=sci_arttext\&pid=S1516-35982001000700003 >. DOI: http://dx.doi.org/10.1590/S1516-35982001000700003.

VAZ, M. M.; TORQUATO, V. C.; BARBOSA, N. D. C. Guia Ilustrado de Peixes da Bacia do Rio Grande. Belo Horizonte: CEMIG/CETEC, 2000, 144p. 